Original Article

\title{
The effects of treatment room lighting color on time perception and emotion
}

\author{
Seulki Han, PhD, $\mathrm{PT}^{1)}$, Daehee LeE, PhD, $\mathrm{PT}^{1)^{*}}$ \\ 1) Department of Physical Therapy, U1 University: 12 Youngdong-eup, Youngdong-gun, Chungbuk \\ 370-701, Republic of Korea
}

\begin{abstract}
Purpose] The purpose of this study was to investigate the perceived treatment times and emotional reactions under different light colors in the treatment room. [Subjects and Methods] Subjects in this study were 20 healthy young students in their 20s. Under each lighting condition (blue, red, white, and yellow) differentiated by color, each subject laid on a therapeutic bed and underwent ultrasound therapy. Subjects were instructed to press a stopwatch every 1 minute, for a total of 5 times, after therapy started according to their perception of time while the stopwatch's time indicator was blocked. After the experiments, self-administered questionnaires were given to subjects to measure their emotional reactions. [Results] In terms of K-POMS scores, the mood states of depressiondejection, anger-hostility, and confusion-bewilderment were higher scores for blue and red lights compared to yellow light. The mood state of vigor-activity were higher scores for yellow and white lights compared to blue and red lights. [Conclusion] Therefore, it is important to take necessary measures to prevent the negative effects that blue and red light-based therapy can have on patient mood.

Key words: Color, Lighting, Time
\end{abstract}

(This article was submitted Apr. 14, 2017, and was accepted Apr. 27, 2017)

\section{INTRODUCTION}

The interior design of health care facilities is crucial to improving patient satisfaction; therefore, the psychological needs of patients and their caregivers and the functional elements of the facilities need to be considered ${ }^{1-3}$.

Patients and their caregivers commonly perceive time passing in hospitals. They want to receive treatment for as long as necessary, but they also want to keep their waiting time as short as possible; therefore, patient satisfaction is affected accordingly ${ }^{4-6)}$. The perception of time is affected by the color of interior spaces ${ }^{7}$. In addition, various psychological responses to interior colors have impacts on treatment outcomes and patient satisfaction ${ }^{8}$.

Furthermore, color is involved in phototherapy, which primarily uses infrared light and ultraviolet radiation and exposes patients to red and blue lights. Light and color not only affect the visual environment but also affect physiological and psychological satisfaction. Gerard described that exposure to blue light led to an overall reduction in physiological aspects and an increase in relaxation and psychological comfort ${ }^{9}$. Woo-seok reported that warm colors used for lighting were associated with perceived fast response times but decreased accuracy ${ }^{10)}$. Jin-hee reported that yellow light triggers positive emotions and activities ${ }^{8}$.

There have been some studies of clinical settings ${ }^{11-13)}$. However, studies investigating time perception and emotional reactions based on the light color of the treatment area are scarce. The purpose of this study was to investigate the perceived treatment times and emotional reactions under different light colors in the treatment room.

\footnotetext{
*Corresponding author. Daehee Lee (E-mail: lovewisd@gmail.com)

(C)2017 The Society of Physical Therapy Science. Published by IPEC Inc.

This is an open-access article distributed under the terms of the Creative Commons Attribution Non-Commercial No Derivatives (by-nc-nd) License. (CC-BY-NC-ND 4.0: https://creativecommons.org/licenses/by-nc-nd/4.0/)
} 
Table 1. Comparison of time perception according to changing light color $(\mathrm{n}=20)$

\begin{tabular}{cccc}
\hline \multicolumn{4}{c}{ Mean \pm SD $(\mathrm{s})$} \\
\hline Blue & Red & White & Yellow \\
\hline $70.5 \pm 27.5$ & $78.7 \pm 22.2$ & $73.7 \pm 16.6$ & $76.2 \pm 24.4$ \\
\hline
\end{tabular}

Table 2. Comparison of K-POMS according to change light color $(\mathrm{n}=20)$

\begin{tabular}{|c|c|c|c|c|c|}
\hline & \multicolumn{4}{|c|}{ Mean \pm SD (score) } & \multirow{2}{*}{ Post-hoc ${ }^{\mathrm{a}}$} \\
\hline & Blue & Red & White & Yellow & \\
\hline Tension-Anxiety & $4.6 \pm 3.3$ & $4.3 \pm 2.7$ & $3.3 \pm 2.7$ & $3.3 \pm 1.8$ & - \\
\hline Fatigue-Inertia & $6.7 \pm 6.0$ & $4.0 \pm 5.5$ & $3.2 \pm 2.8$ & $4.4 \pm 4.0$ & - \\
\hline Depression-Dejection $^{* *}$ & $6.9 \pm 9.1$ & $2.6 \pm 3.0$ & $1.1 \pm 2.2$ & $0.1 \pm 0.4$ & $\mathrm{~B}, \mathrm{~L}>\mathrm{L}, \mathrm{W}>\mathrm{Y}$ \\
\hline Anger-Hostility* & $1.1 \pm 1.9$ & $0.4 \pm 0.8$ & $0.3 \pm 0.9$ & $0.0 \pm 0.0$ & $\mathrm{~B}, \mathrm{~L}, \mathrm{~W}>\mathrm{L}, \mathrm{W}, \mathrm{Y}$ \\
\hline Confusion-Bewilderment ${ }^{*}$ & $2.4 \pm 2.4$ & $2.3 \pm 1.9$ & $1.0 \pm 1.5$ & $0.9 \pm 1.8$ & $\mathrm{~B}, \mathrm{~L}>\mathrm{W}, \mathrm{Y}$ \\
\hline Vigor-Activity $^{* *}$ & $3.1 \pm 5.4$ & $2.9 \pm 4.4$ & $5.3 \pm 5.4$ & $7.0 \pm 6.6$ & $\mathrm{Y}, \mathrm{W}>\mathrm{W}, \mathrm{B}>\mathrm{B}, \mathrm{L}$ \\
\hline
\end{tabular}

\section{SUBJECTS AND METHODS}

Subjects in this study were 20 healthy young students in their 20 s. The mean age, height, and weight of the subjects were $22.7 \pm 1.8$ years, $169.2 \pm 5.3 \mathrm{~cm}$, and $71.9 \pm 10.8 \mathrm{~kg}$, respectively. Ethical approval for the study was granted by the Institutional Review Board of U1 University (Bioethics 2017-3). All subjects were fully informed of the objectives and methods of the study beforehand and provided informed consent to participate in the experiments.

The room where the experiments were performed had white walls, white ceiling, and white floor and used blackout curtains and thick paper to keep out any of external light. The lighting devices were smart LED lightings (hue; Philips, Netherlands). Illuminance was fixed at 150 lux for all lighting conditions. An illuminometer (LX-1010B; Vetus, China) and a color difference meter (TES-135A, TES, Taiwan) were used to ensure consistency of color produced for each experiment.

To minimize learning effects on study results associated with repeated experiments, light colors were used in random order and only one light color was used per day for measurements.

Subjects were instructed to stay in a dark room for 3 minutes before being exposed to the prepared lighting conditions (blue, red, white, and yellow). Under each lighting condition differentiated by color, each subject laid on a therapeutic bed and underwent ultrasound therapy, with the intensity set at 0 . During ultrasound therapy, subjects were instructed to press a stopwatch every 1 minute, for a total of 5 times, after therapy started according to their perception of time while the stopwatch's time indicator was blocked. After the experiments, self-administered questionnaires were given to subjects to measure their emotional reactions.

Statistical analysis was performed using SPSS 18.0; a statistical significance level of 0.05 was used. Friedman test was used to determine differences in the ability to perceive time and K-POMS (Korean Edition of Profile of Mood States) scores. Post hoc analysis was performed using a Wilcoxon Sing test.

\section{RESULTS}

The mean values of time perception with different light colors were not statistically significant ( $\mathrm{p}>0.05)$ (Table 1).

In terms of K-POMS scores, tension-anxiety and fatigue-inertia showed no significant differences with respect to different light colors $(\mathrm{p}>0.05)$. However, the mood states of depression-dejection, anger-hostility, and confusion-bewilderment were significantly different according to light colors, with higher scores for blue and red lights compared to yellow light $(\mathrm{p}<0.05)$. The mood state of vigor-activity varied with light colors, with higher scores for yellow and white lights compared to blue and red lights $(\mathrm{p}<0.05)$ (Table 2).

\section{DISCUSSION}

Based on the results of the experiments, there were no significant differences in tension-anxiety and fatigue-inertia factors. This can be explained by the familiarity the subjects felt because the experiment laboratory was prepared identically to the treatment room that they had frequently visited, thereby allowing them to relax. Furthermore, the mood states of tension and fatigue were more likely induced by labor intensity or work proficiency than light color ${ }^{14)}$.

Previous studies reported that blue tended to trigger negative emotional states such as depression, whereas yellow trig- 
gered positive emotional states of being cheerful and delightful ${ }^{15)}$. In this study, the scores of the depression-dejection, anger-hostility, and confusion-bewilderment factors were significantly higher for blue light than for yellow light, whereas the score for the vigor-activity factor was significantly lower for blue light than for yellow light. These findings signify that patients may be more susceptible to depression, anger, inertia, and confusion under blue light in clinical settings. In contrast, it was found that yellow and white lights can help patients to be positive, stable, active, and focused. Therefore, the use of yellow lights can be suitable for settings where active therapy is required, including pediatric physical therapy and exercise therapy rooms.

Patients may be prone to depression in addition to physical injury ${ }^{16,17)}$. For example, patients with skin disease such as psoriasis and vitiligo may report severe depression as a result of being separated from others socially and emotionally ${ }^{18)}$. These patients undergo light therapy using ultraviolet rays, particularly natural blue lights. The results of this study suggest the possibility that such blue light-based therapy may cause patients to feel more depressed. Therefore, it is important to take necessary measures to prevent the negative effects that blue light-based therapy can have on patient mood. For instance, wearing colored glasses that do not recognize blue color or installing a screen to block blue light can be recommended to protect patient mood.

This study examined only healthy subjects in their 20 s in a certain geographic area. Therefore, future studies should target a wider variety of subjects in terms of region, age, and disease. In addition, they should involve a wider variety of postures and various muscles.

The purpose of this study was to investigate the perceived treatment times and emotional reactions under different light colors in the treatment room. It is important to take necessary measures to prevent the negative effects that blue light-based therapy can have on patient mood. For instance, wearing colored glasses that do not recognize blue color or installing a screen to block blue light can be recommended to protect patient mood.

This study was concerned only with healthy subjects in their twenties in a certain geographic area, and the number of subjects was small. Therefore, in the future, an experiment with a larger number of subjects with more-diverse diseases should be conducted.

\section{REFERENCES}

1) Sin MK: Study on the color systems of dental clinics. Yonsei University, Graduation master's thesis. 2004.

2) Jung SW, Seo YJ, Lee HJ, et al.: Determinants of patient satisfaction and intent to revisit at national university hospitals in Korea. Korean J Hosp Manage, 2005, 10: 1-25.

3) Kim JS: Effect of physical environment of hospital on customer' satisfaction and worth of mouth, revisit intention. J Korea Acad Industr Coop Soc, 2012, 13: 4645-4652. [CrossRef]

4) Kwon CS, Han DW: A Study on patients' satisfaction for quality improvement of physical therapy sevice. J Korean Phys Ther, 2000, 7: 483-494.

5) Kim G, Lee HK, Koo BO, et al.: A Study of satisfaction of time management regarding manual therapy of hemiplegic patient and guardian. J Health Sci, 2002, 3: $181-197$.

6) Kim SY: Factors affecting out patient satisfaction with physical therapy service. J Korean Phys Ther, 1990, 11: 1-18.

7) Suk HJ, Kim GM: The influence of chromacity of LED lighting on time perception. J Korean Saf Emotion Sens, 2010, 13: 69-78.

8) Park JH: A study on influence of lighting color and illuminance on mood state. Ewha University, Graduation master's thesis. 2014.

9) Birren F: Color psychology and color therapy; a factual study of the influence of color on human life. Pickle Partners Publishing, 2016.

10) Jung WS, Kim GB, Kwon DK, et al.: The effects of stimulation resulting from colorful lights on cognitive functions. J Korean Precis Eng, 2007 , 24 : 131-136.

11) Park SW, Back YH, Seo JS, et al.: The literatural review of world physical therapy environment—focus on world confederation for physical therapy-. J Korean Soc Health Sci, 2005, 12: 56-71.

12) Shin HK, Lee TK, Jun JY, et al.: The effect of the physical therapy treatment room environment using microwave diathermy on the autonomic nervous system of human body. J Korean Soc Phys Med, 2015, 10: 37-43. [CrossRef]

13) Lim CH, Kim JS: The effects of electromagnetic fields shielding on electromagnetic fields decrease in PT room. J Korean Phys Ther, 2000, 12 : 69-82.

14) Jang TI, Lim HK: Analysis of mental fatigue of inspection workers under various lighting conditions. J Korean Saf, 2006, 21: 114-120.

15) Walker M: The power of color. New York: Avert Pub Group, 1991

16) You JE, Jung EH: The effects of traditional physical therapy on pain reduction and depression level of patients with chronic low back pain. J Korean Phys Ther, 2001, 13: 677-683.

17) Moussavi S, Chatterji S, Verdes E, et al.: Depression, chronic diseases, and decrements in health: results from the World Health Surveys. Lancet, 2007, 370 : 851-858. [Medline] [CrossRef]

18) Park JW: Physical therapy intervention for skin diseases. Seoul: Panmun Education, 2015. 